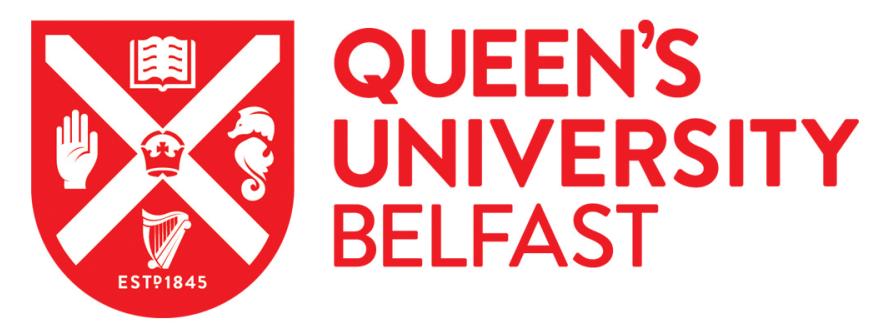

\title{
Investigation of glycerol hydrogen-bonding networks in choline chloride/glycerol eutectic-forming liquids using neutron diffraction
}

Holbrey, J., \& Turner, A. (2019). Investigation of glycerol hydrogen-bonding networks in choline chloride/glycerol eutectic-forming liquids using neutron diffraction. Physical Chemistry Chemical Physics (PCCP), 21, 2178221789,. https://doi.org/10.1039/C9CP04343H

Published in:

Physical Chemistry Chemical Physics (PCCP)

Document Version:

Peer reviewed version

Queen's University Belfast - Research Portal:

Link to publication record in Queen's University Belfast Research Portal

Publisher rights

Copyright 2019 Royal Society of Chemistry. This work is made available online in accordance with the publisher's policies. Please refer to any applicable terms of use of the publisher.

\section{General rights}

Copyright for the publications made accessible via the Queen's University Belfast Research Portal is retained by the author(s) and / or other copyright owners and it is a condition of accessing these publications that users recognise and abide by the legal requirements associated with these rights.

Take down policy

The Research Portal is Queen's institutional repository that provides access to Queen's research output. Every effort has been made to ensure that content in the Research Portal does not infringe any person's rights, or applicable UK laws. If you discover content in the Research Portal that you believe breaches copyright or violates any law, please contact openaccess@qub.ac.uk. 


\title{
Investigation of glycerol hydrogen-bonding networks in choline chloride/glycerol eutectic-forming liquids using neutron diffraction ${ }^{\dagger}$
}

\author{
Adam H. Turner ${ }^{a, b}$ and John D. Holbrey ${ }^{a}$ \\ a The QUILL Research Centre, School of Chemistry and Chemical Engineering, Queen's University \\ Belfast, Belfast BT9 5AG, UK. Tel: +44 (0) 289097 5479; E-mail: j.holbrey@qub.ac.uk \\ ${ }^{b}$ Department of Chemistry, Ateneo de Manila University, Quezon City 1108, Philippines. Tel: +63 2426 \\ 6001; E-mail: aturner@ateneo.edu
}

\begin{abstract}
Abstact
The structure of choline chloride/glycerol (ChCl:Gly) mixtures at two mole fractions (the eutectic $\chi_{\mathrm{ChCl}}=0.33(1: 2)$, and a higher $\chi_{\mathrm{ChCl}}=0.50$ (1:1) composition) in the liquid state at $333 \mathrm{~K}$ and $1 \mathrm{~atm}$. has been investigated using neutron diffraction coupled with hydrogen/deuterium isotopic substitution. Modelling using the empirical potential structure refinement (EPSR) technique, constrained to the experimental neutron diffraction data, produced structural models at both compositions consistent with the experimental data with an extensive, persistent homo-molecular glycerol hydrogen bonding network at $\chi_{\mathrm{ChCl}}=0.33$ similar to that present in pure glycerol and suggests that persistence of the latent glycerol hydrogen bonding network is key to formation of the ChCl:Gly deep eutectic solvent. In the choline chloride-rich $\chi_{\mathrm{ChCl}}=0.50$ composition, significant domain segregation is observed with a dramatic reduction in the extent of the homo-molecular glycerol hydrogen bond network which is replaced by a more homogeneous system-wide hydrogen bonded network incorporating glycerol, $\mathrm{Cl}^{-}$, and choline cations.
\end{abstract}

\section{Introduction}

Deep eutectic solvents (DES), ${ }^{1}$ draw their heritage from the development of room temperature ionic liquids and exhibit many common characteristics. Like ionic liquids, ${ }^{2}$ DES have been explored as replacements for conventional organic solvents for chemical, electrochemical, and extraction applications. ${ }^{3}$ DES are exemplified by choline chloride:urea (ChCl:U, $\left.\chi_{\mathrm{ChCl}}=0.33,1: 2\right)^{4}$ and choline chloride:glycerol (ChCl:Gly, $\left.\chi_{\mathrm{ChCl}}=0.33,1: 2\right)^{5}$ mixtures where the melting/freezing points of the liquids are reduced by as much as $178{ }^{\circ} \mathrm{C}$ relative to their individual components.

The formation of lower melting glycerol/choline chloride mixtures is of interest to understanding, and modify, the behaviour of glycerol as a cryoprotectant or a working fluid component. Glycerol is used in nature as an antifreeze in a divergent range of organisms including bacteria, yeasts, plants, insects, fish and reptiles ${ }^{6}$ and has been applied as a component for low temperature storage of biological and pharmaceutical materials. Liquid glycerol exhibits an extended hydrogen bond network ${ }^{7}$ with intramolecular hydrogen bonding playing the dominant role in the dynamic liquid structure that contains a range of mobile glycerol conformers with ca. 6 hydrogen bonds per molecule. ${ }^{8}$ This distributed hydrogen bond network is largely unaffected by inclusion of hydrogen bonding guest molecules or diluents such as water, ${ }^{9}$ and this allows glycerol to act as an efficient

$\dagger$ Electronic Supplementary Information (ESI) available: reference potentials, molecular geometries, viscosity data and pRDFs for ChCl:Gly, $\chi_{\mathrm{ChCl}}=0.50$. 
glass-forming cryoprotectant in which preferential hydration ${ }^{10}$ hinders initial nucleation, and subsequent crystallisation, of both glycerol and ice-forming free water components. ${ }^{11}$

The ChCl:Gly eutectic $\left(\chi_{\mathrm{ChCl}}=0.33\right)$ has a viscosity around $3 \times$ lower than pure glycerol with values at room temperature of $400 \mathrm{cP}^{5}$ and $281 \mathrm{cP}^{12}$ reported. This, coupled with the suppression of freezing evident by formation of the eutectic $\left(T_{m}=-40{ }^{\circ} \mathrm{C}\right.$ compared to $17.8{ }^{\circ} \mathrm{C}$ for glycerol), makes ChCl:Gly DES interesting as potential substitutes for pure glycerol that can address high viscosity limitations.

It is worth noting that while it has been proposed that this reduction in viscosity is due to disruption of the glycerol network structure reducing the average number of glycerol-glycerol hydrogen bonds. This contrasts with an increase in viscosity and propagation of hydrogen bonding chains in non-eutectic choline chloride:ethylene glycol mixtures, ${ }^{13}$ and the persistence of extensive hydrogen bond networks in $\mathrm{ChCl}$ :polyol liquids is supported by polarity measurements, ${ }^{14}$ vibrational spectroscopy ${ }^{15}$ and modelling. ${ }^{16}$ Most recently, collective dynamic relaxation profiles of the ChCl:Gly $\left(\chi_{\mathrm{ChCl}}=0.33\right)$ liquid have been examined using broadband dielectric and neutron spin echo spectroscopy. ${ }^{17} \mathrm{ChCl}$ :Gly mixtures show rapid dynamics uncorrelated with general DES viscosity trends, ${ }^{18}$ in which rapid short-range diffusivity is observed for choline cations ${ }^{19}$ and contrasts with slower long range dynamics of the glycerol component. ${ }^{5,20,21}$ This suggests that choline cations have freedom to diffuse locally within interstitial voids in the DES, which is constructed from a locally defined and spatially constrained network structure between hydrogen bonded glycerol molecules and between glycerol and chloride anions, with choline cations acting as a plasticiser to the network.

Computational studies, using non-polarisable force fields combined with scaled charged, ${ }^{22}$ AIMD, ${ }^{23}$ and OPLS-DES ${ }^{24}$ force fields predict that the strongest hydrogen bonds in ChCl:Gly $\left(\chi_{\mathrm{ChCl}}=0.33\right)$ are between $\mathrm{Cl}^{-}$and glycerol-OH groups, with the most dominant interaction from $\mathrm{Cl}^{-}$to the central -OH of glycerol (OC). However, as the molar conductivity in ChCl:Gly mixtures increases with $\chi_{\mathrm{ChCl}}{ }^{5,25}$ it is clear that $\mathrm{Cl}^{-}$anions are not confined by complexation with glycerol.

Here, the changes in, and retention of, the glycerol intermolecular hydrogen bonding network between two liquid ChCl:Gly compositions $\left(\chi_{\mathrm{ChCl}}=0.33\right.$ and 0.50$)$ comprising of the 1:2 eutectic and a choline chloride-rich 1:1 mixture are investigated using experimental neutron scattering data combined with EPSR structure analysis. The results indicate that the local structure of the liquids remains similar between the two compositions with hetero-hydrogen-bond formation key to melting point reduction. Analysis of hydrogen-bonding in the system reveals that a glycerol only network is diminished in $\chi_{\mathrm{ChCl}}=0.50$ but that system wide networks remain consistent with the $\chi_{\mathrm{ChCl}}=0.33$ system.

\section{Experimental}

Hydrogenated choline chloride, glycerol and glycerol- $d_{8}$ were purchased from Sigma-Aldrich. Choline chloride- $d_{9}$ was purchased from CDN Isotopes (QMX Laboratories, Thaxted, UK). All samples were used as received without further purification.

Seven samples of ChCl:Gly with differing hydrogen-deuterium isotopic contrast (H:D, D:H, H:H, D:D, H/D:H/D, H/D:D, and D:H/D) were prepared at compositions for both ChCl:Gly compositions, $\chi_{\mathrm{ChCl}}=0.33$ and 0.50 using appropriate molar ratios of either deuteriated or protiated choline 
chloride and glycerol at $60{ }^{\circ} \mathrm{C}$ under an inert atmosphere. As a representative example, glycerol $(1.58 \mathrm{~g}, 17.2 \mathrm{mmol})$ was added to choline chloride $(1.2 \mathrm{~g}, 8.6 \mathrm{mmol})$ and heated at $60^{\circ} \mathrm{C}$ to produce the protiated $\chi_{\mathrm{ChCl}}=0.33$ DES as a liquid.

Neutron scattering data were collected at the ISIS pulsed neutron and muon source at the Rutherford Appleton Laboratory, UK, using the SANDALS spectrometer. Each sample was measured in a "null scattering" $\mathrm{Ti}_{0.68} \mathrm{Zr}_{0.32}$ flat plate cell each with internal geometries of $1 \times 35 \times 35$ $\mathrm{mm}$, with a wall thickness of $1 \mathrm{~mm}$. During the measurements, the temperature was maintained at $333 \mathrm{~K}$ (above the melting point of the $\chi_{\mathrm{ChCl}}=0.50$ samples) using a Julabo FP50 recirculating heater. Measurements were made for the purposes of instrument calibration and data normalisation on each of the empty sample holders, the empty spectrometer, and a $3.1 \mathrm{~mm}$ thick vanadium standard sample.

Data reduction was performed using GUDRUN ${ }^{26}$ to produce a differential scattering cross section for each experimental sample. The experimental sample densities and scattering levels were consistent with the actual isotopic compositions of the samples. Differential scattering cross sections were prepared from each sample by subtracting for single atom scattering using the calibration and background data. These experimental data-sets were then analysed using the Empirical Potential Structure Refinement (EPSR) program. ${ }^{27}$

The experimental total structure factors, $\mathrm{F}(Q)$, were extracted from the neutron scattering data for each of the isotopically distinct samples at each composition. These were used used to build and refine EPSR derived three dimensional models of each liquid consistent with the experimental data. From the differences between the experimental and calculated structure factors in $Q$-space for each data-set, an empirical perturbation potential is determined. This empirical potential is combined with the reference potential and used to iteratively drive the simulation towards agreement with the experimental data.

[Fig. 1 about here.]

The EPSR calculations were performed using 400 choline chloride ion pairs and 800 glycerol molecules ( $\mathrm{ChCl}: \mathrm{Gly} \chi_{\mathrm{ChCl}}=0.33$ ), and 500 choline chloride ion pairs and 500 glycerol molecules (ChCl:Gly $\left.\chi_{\mathrm{ChCl}}=0.50\right)$. The simulations were performed using cubic dimensions of $58.26 \AA$, and $55.80 \AA$ respectively. EPSR models were refined against the full experimental data range $(Q=0.1-$ $50 \AA^{-1}$ ). Atom types for each system were defined based on their position in the molecular skeleton as shown in Figure 1, full rotational flexibility was enabled for the model. Reference potential parameters are given in the ESI in Table S1, †interatomic distance and angular constraints used to define the basic molecular geometries are summarised in Table S2. $\dagger$

Simulations were allowed to equilibrate for at least 5000 cycles before applying the empirical potential and then were equilibrated over ca. 30000 cycles before accumulating data. The total numeric density of the simulation box corresponded to the experimentally determined molecular densities of the fully protiated materials $\left(1.172 \mathrm{~g} \mathrm{~cm}^{-1}\right.$ and $1.151 \mathrm{~g} \mathrm{~cm}^{-1}$ for $\chi_{\mathrm{ChCl}}=0.33$ and 0.50 , respectively). Viscosity data for both compositions as a function of temperature can be found in the ESI.†Centre of mass radial distribution functions (RDFs) were calculated using the SHARM routines with EPSR. 


\section{Results}

\section{Experimental neutron diffraction data and fits}

Experimental data was collected from liquid ChCl:Gly compositions $\left(\chi_{\mathrm{ChCl}}=0.33\right.$ and 0.50$)$ at $333 \mathrm{~K}$. Data was modelled using EPSR, continuously refining against the experimental data obtained at each different composition with results seen in Figure 2 showing good agreement between experimental data and EPSR derived models.

[Fig. 2 about here.]

Centre of mass radial distribution functions (RDFs - Figure 3) were calculated between the three components, choline, $\mathrm{Cl}^{-}$and glycerol using the EPSR model. The position of the first peak $\left(r_{\max }\right)$ in the RDFs is shown in Table 1. These RDFs are comparable to those previously reported for choline chloride eutectic liquids with urea, oxalic and malonic acid ${ }^{28-30}$ and agree well with computational studies. ${ }^{31,32}$

[Fig. 3 about here.]

[Table 1 about here.]

The RDFs from both compositions are similar and reveal well defined choline- $\mathrm{Cl}^{-}$and glycerol$\mathrm{Cl}^{-}$association. For the ChCl:Gly $\chi_{\mathrm{ChCl}}=0.33$ composition, the $\mathrm{RDF}$ show the choline- $\mathrm{Cl}^{-}$association with a first peak at $4.1 \AA$ and a secondary correlation peak at $5 \AA$. The choline-glycerol first shell correlation occurs with a maximum at $5.9 \AA$. The glycerol- $\mathrm{Cl}^{-}$peak is at $4.1 \AA$ with the glycerol-glycerol peak at $5.3 \AA$ falling between the glycerol- $\mathrm{Cl}^{-}$and glycerol-choline peaks. The first choline-choline peak in the RDF is found at $6.5 \AA$ indicating that this is a second shell association.

[Table 2 about here.]

Increasing the choline content to $\chi_{\mathrm{ChCl}}=0.50$ does not result in any changes in the ordering of the RDFs, hence no significant changes in the local structure, but does induce small shifts in position of the first correlation maxima and a general broadening of each RDF. The relative molecular associations apparent from the RDFs are consistent with simulation ${ }^{22,31,32}$ and with the general behaviour of a range of choline-based DES when the relative sizes of the molecular components are taken into account. ${ }^{30,33}$ On increasing the proportion of choline chloride in the system, from $\chi_{\mathrm{ChCl}}$ $=0.33$ to 0.50 , a small contraction in the positions of $r_{\text {max }}$ for the choline-choline and $\mathrm{Cl}^{-}$-glycerol correlations and a small increase in the glycerol-glycerol $r_{\max }$ is evident, although this contrasts with a small (0.2 $\AA$ ) decrease in the CC-CC partial RDF from 5.2 to $5.0 \AA$. The choline- $\mathrm{Cl}^{-}$and glycerol- $\mathrm{Cl}^{-}$RDFs both show first maxima at $4.1 \AA$ with a second peak at $4.9 \AA$. The first maximum in the choline- $\mathrm{Cl}^{-}$correlation occurs at a shorter distance in the higher choline chloride content liquid $\left(\chi_{\mathrm{ChCl}}=0.50\right)$ than in the $\chi_{\mathrm{ChCl}}=0.33$ DES. The glycerol-glycerol and choline-glycerol interactions are centred at 5.5 and $5.7 \AA$, the former being longer and the latter being shorter than in the $\chi_{\mathrm{ChCl}}=0.33$ system. Similarly, a small reduction in the choline-choline correlation distance is also observed, from $6.5 \AA$ to $6.3 \AA$ in the $\chi_{\mathrm{ChCl}}=0.50$ liquid. 
The double peak pattern with maxima at 4.1 and $4.9 \AA$ between choline and $\mathrm{Cl}^{-}$is observed at both compositions, and reflects the presence of two distinct $\mathrm{Cl}^{-}$population centres relative to choline, one that is $\mathrm{N}$ centred (4.1 $\mathrm{\AA}$ ) and another that is OH centred (4.9 $\mathrm{A}$ ).

[Fig. 4 about here.]

It is apparent, that anion-cation ordering is present at both compositions, consistent with previous examination of high concentration organic salt/solute systems where concentric shell-like structures are observed. However, this pattern differs from that ethylammonium formate/glycerol mixtures ${ }^{34}$ where glycerol molecules were preferentially incorporated into charged domains forming hydrogen bonds with ethylammonium formate ions rather than to glycerol molecules. This was ascribed to the strongly hydrogen bonding nature of the small, charged ammonium and formate ions in the mixtures, and contrasts with the larger, and more diffuse choline cation here.

Strong hydrogen bond interactions were observed between the chloride anion and both the glycerol and choline, with the choline-chloride interactions indicating that the anion sits in a region between the hydroxyl moiety and the nitrogen containing head-group. Glycerol-chloride interactions are predominantly hydrogen bonding in nature, with a pronounced first correlation peak between the glycerol-OH hydrogens and $\mathrm{Cl}^{-}$at $2.1 \AA$.

Increasing the choline chloride concentration from $\chi_{\mathrm{ChCl}}=0.33$ to 0.50 causes an increase in the choline-choline and choline- $\mathrm{Cl}^{-}$interactions, although by less than might be anticipated for the $50 \%$ increase in choline chloride concentration, with correlations to the ammonium head group strengthening while tail-head group correlations weaken. The corresponding choline-glycerol interactions generally weaken whilst $\mathrm{Cl}^{-}$-glycerol interactions are unchanged. Coordination numbers for the various site-site partial radial distributions (pRDFs - Figure 4) are shown in Table 2. While the position of $r_{\max }$ (the peak maximum of the $\mathrm{pRDF}$ ) varies between the compositions, the first minimum after this peak $\left(r_{\min }\right)$ did not change with composition.

The eutectic 1:2 ChCl:Gly $\left(\chi_{\mathrm{ChCl}}=0.33\right)$ composition has the lowest melting point of choline chloride-glycerol mixtures and thus represents the point of greatest disruption of the two individual components and can be compared to other similar DES such as ChCl: $\mathrm{U}\left(\chi_{\mathrm{ChCl}}=0.33\right)$ and $\mathrm{ChCl:Ox}$ $\left(\chi_{\mathrm{ChCl}}=0.50\right)$. The choline centre of mass lies along the $\mathrm{N}-\mathrm{CE}$ bond, thus the CE-CE and CE-Cl pRDFs are approximations of the respective COM RDFs and have coordination numbers of 4.8 and 1.6. These coordination numbers are lower than those previously reported for other similar choline chloride-containing DES such as $\mathrm{ChCl}: \mathrm{U}\left(\chi_{\mathrm{ChCl}}=0.33\right)$ and $\mathrm{ChCl}: \mathrm{Ox}\left(\chi_{\mathrm{ChCl}}=0.50\right)$ albeit over slightly shorter distances. ${ }^{30}$

The $\mathrm{N} \cdots \mathrm{Cl}$ correlation $\left(r_{\max }=4.2 \AA\right.$ ) has a coordination number of 3.1 calculated to the first minimum after this peak $\left(r_{\min }\right)$. The $r_{\max }$ observed here, at $333 \mathrm{~K}$, is similar to those found in ChCl:Mal and ChCl:U at 298/303 $\mathrm{K}^{28,29}$ and is ca. $0.5 \AA$ longer than that found at $338 \mathrm{~K}$ for the $\mathrm{ChCl}: \mathrm{U}$ and $\mathrm{ChCl}: \mathrm{Ox}$ DES. The $\mathrm{CE} \cdots \mathrm{Cl}$ correlation has a clear bimodal distribution either side of the $\mathrm{N} \cdots \mathrm{Cl}$ correlation similar to that seen for other DES. ${ }^{30}$ Unlike these previously reported liquids, the distribution shows no distance preference with peak length as both the distribution from 0 to 5.1 $\AA$ and that centred around the $5.6 \AA$ peak have the same coordination number of 2.1 . The $\mathrm{N} \cdots \mathrm{Cl}$ correlation with $r_{\max }=4.2 \AA$ shows only a single distribution unlike the two-peak or peak-shoulder arrangement described for other DES. ${ }^{28-30}$ This suggests that $\mathrm{Cl}^{-}$anions have a greatest correlation 
through ion-ion attraction with the charged choline cation $\mathrm{N}$-centre rather than through hydrogen bonding to the hydroxyl moiety. ${ }^{28,32,35}$ This is reflected in the significantly lower coordination number for the $\mathrm{HO} \cdots \mathrm{Cl}$ interaction which has a first shell maximum at $2.2 \AA$ with coordination number of 0.4. This is consistent with previous MD studies where correlation distances around $\sim 2 \AA$ with coordination number of 0.52 reported. ${ }^{32}$ However, compared to previous investigations on DES using neutron scattering, ${ }^{28-30}$ the $\mathrm{Cl}^{-}$anion is less associated with the choline-OH site.

$\mathrm{Cl}^{-}$also coordinates to the glycerol molecules. Contact correlations between $\mathrm{Cl}^{-}$and glycerol H-sites occur in the RDFs from $2.1 \AA$ with coordination numbers of 3.2 (1:2) and 2.1 (1:1), indicating these are slightly stronger interactions than the hydrogen bonding between $\mathrm{Cl}^{-}$and choline-hydroxyl sites. OPLS MD simulations ${ }^{24}$ have also shown a preference for OC...Cl over $\mathrm{O} \cdots \mathrm{Cl}$ interactions.

Glycerol-glycerol self-association is evident in both liquid compositions from the correlation peak in the COM RDFs at $5.3 \AA$ and the corresponding CC...CC pRDF correlation peak at $5.2 \AA$. Increasing the choline chloride concentration causes an expansion of the glycerol-glycerol network as the self-association lengthens in the COM RDF but without significant reduction in correlation strengths (pRDFs). Thus it appears that the increase in hetero-hydrogen bonds allows the formation of the ChCl:Gly (1:2) DES.

\section{Spatial Density Functions}

Spatial density functions (SDFs) of choline, chloride, and glycerol centred around either the choline or glycerol molecules in the ChCl:Gly $\left(\chi_{\mathrm{ChCl}}=0.33\right.$ and 0.50$)$ EPSR models are shown in Figure 5. Both systems display comparable distributions of components around the centres of masses of both the choline and glycerol molecules.

The closest contact in the choline-centred SDFs is with $\mathrm{Cl}^{-}$for both compositions (at a contact distance of $4.1 \AA$ ) with the highest probability of correlation around the ammonium moiety with density centred as spots between the methyl groups and around the $\mathrm{NCH}_{2} \mathrm{CH}_{2} \mathrm{OH}$ group. Interestingly at this distance, there is no evidence of density around the hydroxyl moiety.

[Fig. 5 about here.]

The SDFs of glycerol around the choline cation again show similar distributions between the concentrations generally centred around the ammonium group but with a larger more diffuse distribution with gaps directly over the methyl moieties. For glycerol SDF in the ChCl:Gly $\left(\chi_{\mathrm{ChCl}}=\right.$ 0.33 ) system shows a greater diffusivity due to the higher concentration and presence over a wider array of configurations.

Correlations of choline cations around choline centres are associated with vacant space unoccupied by either glycerol or $\mathrm{Cl}^{-}$. The SDF is mainly found directly over the methyl groups and at the hydroxyl moiety with a larger more diffuse SDF found for ChCl:Gly $\left(\chi_{\mathrm{ChCl}}=0.50\right)$.

The glycerol centred SDFs show strong correlations with $\mathrm{Cl}^{-}$over the central hydroxyl group and some correlation underneath the molecule between the terminal hydroxyls. The correlation between the terminal groups increases with increasing choline chloride concentration. In general, the choline cation SDF is the furthest from the central molecule and is situated around the $\mathrm{Cl}^{-}$SDF 
but is more diffuse consistent with a strong correlation between the $\mathrm{Cl}^{-}$and glycerol followed by a more diffuse arrangement of choline coordinated with the $\mathrm{Cl}^{-}$.

The glycerol SDF around a central glycerol is highly diffuse and is situated between the $\mathrm{Cl}^{-}$and choline SDFs with some associated with the $\mathrm{OH}$ groups. The strong association of glycerol $\cdots \mathrm{Cl}^{-}$ is anticipated due to the correlation present in the $\mathrm{Cl}-\mathrm{H}$ pRDF. Unlike for ChCl: $\mathrm{U}$ and $\mathrm{ChCl:Ox}$, there is some evidence for glycerol-glycerol hydrogen bond networks seen in the $\mathrm{O}-\mathrm{H}$ correlation at 1.7-1.8 $\AA$ (coordination number 1.2-1.3).

In common to previous examination of $\mathrm{ChCl}$ :Ox and $\mathrm{ChCl}: \mathrm{U}$ DES at moderately elevated temperatures, ${ }^{30}$ strong choline- $\mathrm{OH} \cdots \mathrm{Cl}^{-}$correlations seen at room temperature in choline-chloride-based DES $^{28,29}$ are absent from both the $\mathrm{ChCl}$ :Gly mixtures examined here, supporting the limited importance of the choline hydroxyl group as a functional component to form eutectic liquids. However, in contrast to small, and relatively rigid urea and oxalic acid units, glycerol is highly flexible and offers both hydrogen bond donor and acceptor sites that are relatively remote from the glycerol COM resulting in expanded and diffuse RDFs.

\section{Hydrogen bonding}

A key part to understanding how the viscosity of the ChCl:Gly eutectic is reduced compared to that of glycerol depends on evaluation of how the glycerol hydrogen bond network is disrupted by inclusion of glycerol-choline chloride interactions. ${ }^{5}$ Using the definition that a hydrogen bond of the form $\mathrm{X}-\mathrm{H} \cdots \mathrm{Z}$ is generated from the interaction of an $\mathrm{X}-\mathrm{H}$ hydrogen with an electronegative centre, $\mathrm{Z}$, with a maximum $\mathrm{H} \cdots \mathrm{Z}$ distance of $2.5 \AA$, a maximum $\mathrm{X} \cdots \mathrm{Z}$ distance of $3.2 \AA$ and $\mathrm{X}-\mathrm{H} \cdots \mathrm{Z}$ angle of $>135^{\circ},{ }^{36}$ the first peaks in the hydrogen-containing pRDFs in Fig. $4(\mathrm{H} \cdots \mathrm{O}$ and $\mathrm{H} \cdots \mathrm{Cl})$ that have a peak with $r_{\max } c a .2 \AA$ and a minima at $2.5 \AA$ are hydrogen bonding.

[Table 3 about here.]

[Fig. 6 about here.]

Both glycerol-glycerol correlations (OC-H and O-H) have well defined peaks with maxima at 1.8 $\AA$. The coordination numbers for each of these correlations are 1.37 at $\chi_{\mathrm{ChCl}}=0.33$ and are reduced to 1.24 at $\chi_{\mathrm{ChCl}}=0.50$. Comparing the number of glycerol-glycerol hydrogen bonds, in neat glycerol Towey et al. ${ }^{8}$ calculated there were $5.68 \pm 1.51$ hydrogen bonds per glycerol molecule (as both donator and acceptor). Using the same procedure, integrating the distal $(\mathrm{O} \cdots \mathrm{H})$ and central $(\mathrm{OC} \cdots \mathrm{H})$ coordination numbers together in the $\mathrm{ChCl}$ :Gly systems here, the number of glycerolglycerol hydrogen bonds were calculated to be $4.12 \pm 1.6$ at $\chi_{\mathrm{ChCl}}=0.33$, and $3.71 \pm 1.36$ at $\chi_{\mathrm{ChCl}}$ $=0.50$.

The number of glycerol-glycerol hydrogen bonds decreases in ChCl:Gly mixtures compared to neat glycerol. The reduction ( $c$. $10 \%$ ) between $\mathrm{ChCl}$ :Gly compositions is smaller than might be anticipated based on changes in the concentration of glycerol in the mixtures (changing from 1:2 to $1: 1 \mathrm{ChCl}$ :Gly composition is a $25 \%$ reduction in glycerol) but is consistent with the structurally dominant retention of homo-molecular glycerol-glycerol interactions on addition of water. ${ }^{8,37}$

Comparing the relative distributions homo-interactions (OC $\cdots \mathrm{H}, \mathrm{O} \cdots \mathrm{H}, \mathrm{OH} \cdots \mathrm{HO})$ and heterointeractions $(\mathrm{Cl} \cdots \mathrm{H}, \mathrm{Cl} \cdots \mathrm{HO}, \mathrm{OC} \cdots \mathrm{HO}, \mathrm{O} \cdots \mathrm{HO}, \mathrm{OH} \cdots \mathrm{H})$, the choline-choline homo-interactions, 
characterised by $\mathrm{OH} \cdots \mathrm{HO}$, show almost no change with concentration suggesting that the glycerolnetwork is preserved. Increasing the choline chloride content in the liquids from $\chi_{\mathrm{ChCl}}=0.33$ to 0.50 does not promote an increase in intramolecular hydrogen bonding. Rather, from the total of $8.01 \pm 4.13$ hydrogen bonds in the eutectic ChCl:Gly $\left(\chi_{\mathrm{ChCl}}=0.33\right)$ system, $5.13 \pm 1.71$ or $64 \%$ are homo-hydrogen bonds. This decreases to $6.97 \pm 4$ for ChCl:Gly $\left(\chi_{\mathrm{ChCl}}=0.50\right)$ of which $4.73 \pm 1.51$ or $68 \%$ are homo-hydrogen bonds showing that the increase in choline chloride concentration appears to promote a segregation rather than integration of the hydrogen bond network.

This overall reduction in the number of hydrogen bonds in the liquid, without a significant change in the number associated with the glycerol-glycerol network coupled with the observed expansion of the glycerol network volume (evidenced from the COM RDFs) suggests that choline sits in the interstitial voids of the glycerol network. This is corroborated by the consistency of the choline hydrogen bond network between the two compositions.

Snapshots from the EPSR models for ChCl:Gly $\left(\chi_{\mathrm{ChCl}}=0.33\right.$ and 0.50$)$ are shown in Figure 6 along with the calculated distributions of glycerol chains and clusters. Qualitatively, in both $\mathrm{ChCl:Gly} \mathrm{compositions,} \mathrm{highly} \mathrm{interconnected} \mathrm{domains} \mathrm{of} \mathrm{glycerol} \mathrm{and} \mathrm{isolated} \mathrm{choline} \mathrm{cations} \mathrm{are}$ apparent from the cluster analysis, where most glycerol molecules show association with other glycerol molecules whereas most choline cations remain isolated from other cations, but are also highly mixed with glycerol as seen from the similarity in cluster populations for glycerol and glycerol+choline in Figure 6. On increasing the choline chloride content to $\chi_{\mathrm{ChCl}}=0.50$, the clusters remain, but network connectivity is drastically reduced.

At $\chi_{\mathrm{ChCl}}=0.33,9 \%$ of choline cations show correlation through hydroxyl-hydroxyl hydrogen bonding to other choline cations, and this rises to $15 \%$ at $\chi_{\mathrm{ChCl}}=0.50$, indicating that the choline cations are predominantly isolated from other each other in the liquids. In contrast, the glycerol network is highly connected. At $\chi_{\mathrm{ChCl}}=0.33$, glycerol oxygen sites are connected by strong hydrogen bonds (X $\cdots \mathrm{Z}<3.1 \AA$ ) between O-O (25\%) O-OC (20\%) and OC-OC (6\%) sites. In the higher $\chi_{\mathrm{ChCl}}$ system, the number of glycerol oxygen sites participating in clusters of more than two molecules are reduced to 15,13 , and $3 \%$ respectively.

The length of correlated chains of hydrogen bonded glycerol molecules can be calculated from the EPSR simulation, for medium to strong hydrogen bonds between glycerol molecules, there are $20.1 \pm 14.2$ molecules per chain for ChCl:Gly $\left(\chi_{\mathrm{ChCl}}=0.33\right)$ confirming the presence of large interconnected hydrogen bond network that has been proposed from experiments ${ }^{17-20}$ and simulations. ${ }^{16,22,32}$ However, on increasing the choline chloride content to $\chi_{\mathrm{ChCl}}=0.50$, the interconnectedness of the glycerol network is significantly reduced to an average of only $1.3 \pm 1.1$ molecules per chain.

Choline cations also participate in the hydrogen bond networks. When they are included in the analysis chain lengths of $22.0 \pm 12.8$ molecules (1:2) and $1.6 \pm 1.5$ molecules (1:1) with choline forming approximately $15 \%$ of hydrogen bonded chains in both compositions. Analysis of total hetero-hydrogen bonding (including both choline and $\mathrm{Cl}^{-}$) gives $21.3 \pm 5.7$ molecules per chain for ChCl:Gly (1:2) and 23.7 \pm 15.3 for ChCl:Gly (1:1). This large increase in ChCl:Gly (1:1) hydrogen bond correlated chain length on inclusion of $\mathrm{Cl}^{-}$in the analysis corroborates the aforementioned cluster and snapshot data (Figure 6) and suggests that $\mathrm{Cl}^{-}$ions are solvated by the glycerol molecules and act as a connective correlated bridge between $\mathrm{ChCl}$ rich and glycerol rich domains. 
The large error associated with the ChCl:Gly (1:1) compared to ChCl:Gly (1:2) suggests that this structural motif is not continuously present with some larger connected areas and some relatively unconnected areas.

In the ChCl:Gly $\left(\chi_{\mathrm{ChCl}}=0.50\right)$ mixture, the correlation length for glycerol chains is much smaller than in the eutectic ChCl:Gly $\left(\chi_{\mathrm{ChCl}}=0.33\right)$ liquid. This is a result of the reduction in available glycerol molecules and increased disruption of glycerol-glycerol hydrogen bonding due to solvation of chloride anions and leads to the formation of small glycerol clusters dispersed through choline chloride-rich domains compared to the dispersion of dissolved choline in the glycerol network at $\chi_{\mathrm{ChCl}}=0.33$.

\section{Conclusions}

Experimental neutron scattering data was collected for a range of $\mathrm{H} / \mathrm{D}$ isotopically substituted samples of ChCl:Gly at $\chi_{\mathrm{ChCl}}=0.33$ and 0.50 , the $1: 2$ eutectic composition and a $1: 1$ mixture that was richer in choline chloride. For both compositions, the local environments of glycerol, choline cations and $\mathrm{Cl}^{-}$anions are similar, with the pRDFS showing that key inter-component interactions are conserved between compositions. Glycerol forms extensive hydrogen bonds with both other glycerol molecules and also to $\mathrm{Cl}^{-}$anions, that act as a bridge linking glycerol molecules and choline cations. The CC-CC pRDF and hydrogen bonding correlations reveal that the network of glycerol-glycerol hydrogen bonding that is present in pure liquid glycerol ${ }^{8}$ is conserved in the ChCl:Gly $\left(\chi_{\mathrm{ChCl}}=0.33\right)$ eutectic liquid, although the number of glycerol-glycerol hydrogen bond interactions is slightly reduced and is compensated by additional coordination to $\mathrm{Cl}^{-}$anions. At the $\chi_{\mathrm{ChCl}}=0.50$ composition, with a greater fraction of choline chloride, the bulk glycerol-glycerol hydrogen bond network undergoes substantial disruption and reorganisation of the liquid to accommodate the excess choline chloride. This leads to a change in the liquid structure from one dominated by the glycerol network with choline cations dispersed in a continuous glycerol phase to one with isolated small glycerol clusters distributed as a molecular diluent in a predominantly choline chloride 'ionic liquid' environment.

The persistent nature of the glycerol hydrogen-bond network within the greater system wide network points towards how these liquids form a deep eutectic solvent. The choline chloride is

present in sufficient quantities to disrupt the packing and hydrogen bond network of glycerol $\left(\chi_{\mathrm{ChCl}}\right.$ $=0.33$ ) but not at a high enough concentration to cause discrete domain formation $\left(\chi_{\mathrm{ChCl}}=0.50\right)$.

\section{Conflicts of interest}

There are no conflicts to declare.

\section{Acknowledgements}

The authors acknowledge funding and support from the Department for Employment and Learning, Northern Ireland (to AHT), the Science and Technology Facilities Research Council (STFC) for beam-time on SANDALS (ISIS experiment RB1410403), and Dr Samantha K. Callear (ISIS, Rutherford Appleton Laboratory) for support during data collection. AHT would also like to thank the Ateneo de Manila University for the support through the Early Career Support Grant. Data files are freely available from https://doi.org/10.5286/ISIS.E.54815525 in accordance with ISIS data management policy. 


\section{References}

1 E. L. Smith, A. P. Abbott and K. S. Ryder, Chem. Rev., 2014, 114, 11060-11082.

2 J. Estager, J. D. Holbrey and M. Swadźba-Kwaśny, Chem. Soc. Rev., 2014, 43, 847-886.

3 (a) Q. Zhang, K. De Oliveira Vigier, S. Royer and F. Jérôme, Chem. Soc. Rev., 2012, 41, 71087146; (b) L. Yi, J. Feng, W. Li and Z. Luo, ACS Sustainable Chem. Eng., 2019, 7, 7777-7783;

(c) W. M. Wan Mahmood, A. Lorwirachsutee, C. Theodoropoulos and M. Gonzalez-Miquel, ACS Sustainable Chem. Eng., 2019, 7, 5018-5026; (d) A. Grudniewska, E. M. de Melo, A. Chan, R. Gnilka, F. Boratynski and A. S. Matharu, ACS Sustainable Chem. Eng., 2018, 6, 15791-15800.

4 A. P. Abbott, G. Capper, D. L. Davies, R. K. Rasheed and V. Tambyrajah, Chem. Commun., 2003, 70-71.

5 A. P. Abbott, R. C. Harris, K. S. Ryder, C. D'Agostino, L. F. Gladden and M. D. Mantle, Green Chem., 2011, 13, 82-90.

6 P. Yancey, M. Clark, S. Hand, R. Bowlus and G. Somero, Science, 1982, 217, 1214-1222.

7 R. Böhmer and G. Hinze, J. Chem. Phys., 1998, 109, 241-248.

8 J. J. Towey, A. K. Soper and L. Dougan, Phys. Chem. Chem. Phys., 2011, 13, 9397-9406.

9 J. J. Towey, A. K. Soper and L. Dougan, J. Phys. Chem. B, 2011, 115, 7799-7807.

10 (a) L. Dougan, J. Li, C. L. Badilla, B. J. Berne and J. M. Fernandez, Proc. Natl. Acad. Sci., 2009, 106, 12605-12610; (b) K. Gekko and S. N. Timasheff, Biochemistry, 1981, 20, 4667-4676.

11 J. L. Dashnau, N. V. Nucci, K. A. Sharp and J. M. Vanderkooi, J. Phys. Chem. B, 2006, 110, 13670-13677.

12 M. K. AlOmar, M. Hayyan, M. A. Alsaadi, S. Akib, A. Hayyan and M. A. Hashim, J. Mol. Liq., 2016, 215, 98 - 103.

13 A. P. Abbott, R. C. Harris and K. S. Ryder, J. Phys. Chem. B, 2007, 111, 4910-4913.

14 A. Pandey, R. Rai, M. Pal and S. Pandey, Phys. Chem. Chem. Phys., 2014, 16, 1559-68.

15 H. Wang, S. Liu, Y. Zhao, J. Wang and Z. Yu, ACS Sustainable Chem. Eng., 2019, 7, 7760-7767.

16 J. Baz, C. Held, J. Pleiss and N. Hansen, Phys. Chem. Chem. Phys., 2019, 21, 6467-6476.

17 A. Faraone, D. V. Wagle, G. A. Baker, E. C. Novak, M. Ohl, D. Reuter, P. Lunkenheimer, A. Loidl and E. Mamontov, J. Phys. Chem. B, 2018, 122, 1261-1267.

18 A. H. Turner and D. Kim, J. Chem. Phys., 2018, 149, 174503.

19 D. V. Wagle, G. A. Baker and E. Mamontov, J. Phys. Chem. Lett., 2015, 6, 2924-2928.

20 C. D'Agostino, R. C. Harris, A. P. Abbott, L. F. Gladden and M. D. Mantle, Phys. Chem. Chem. Phys., 2011, 13, 21383.

21 C. D’Agostino, L. F. Gladden, M. D. Mantle, A. P. Abbott, E. I. Ahmed, A. Y. M. Al-Murshedi and R. C. Harris, Phys. Chem. Chem. Phys., 2015, 17, 15297-15304.

22 S. Mainberger, M. Kindlein, F. Bezold, E. Elts, M. Minceva and H. Briesen, Mol. Phys., 2017, 115, 1309-1321.

23 A. Korotkevich, D. S. Firaha, A. A. Padua and B. Kirchner, Fluid Phase Equilibria, 2017, 448, 59-68.

24 B. Doherty and O. Acevedo, J. Phys. Chem. B, 2018, 122, 9982-9993.

25 A. P. Abbott, G. Capper, K. J. McKenzie and K. S. Ryder, J. Electroanal. Chem., 2007, 599, 288- 
294.

26 A. K. Soper, GudrunN and GudrunX: Programs for correcting raw neutron and X-ray diffraction data to differential scattering cross section, Rutherford Appleton Laboratory technical report, 2011.

27 (a) A. K. Soper, Chem. Phys., 1996, 202, 295-306; (b) A. K. Soper, Mol. Phys., 2001, 99, 15031516.

28 O. S. Hammond, D. T. Bowron and K. J. Edler, Green Chem., 2016, 18, 2736-2744.

29 O. S. Hammond, D. T. Bowron, A. J. Jackson, T. Arnold, A. Sanchez-Fernandez, N. Tsapatsaris, V. Garcia Sakai and K. J. Edler, J. Phys. Chem. B, 2017, 121, 7473-7483.

30 M. Gilmore, L. M. Moura, A. H. Turner, M. Swadźba-Kwaśny, S. K. Callear, J. A. McCune, O. A. Scherman and J. D. Holbrey, J. Chem. Phys., 2018, 148, 193823.

31 S. L. Perkins, P. Painter and C. M. Colina, J. Chem. Eng. Data, 2014, 59, 3652-3662.

32 R. Stefanovic, M. Ludwig, G. B. Webber, R. Atkin and A. J. Page, Phys. Chem. Chem. Phys., 2017, 19, 3297-3306.

33 O. S. Hammond, D. T. Bowron and K. J. Edler, Angew. Chem. Int. Ed., 2017, 56, 9782-9785.

34 T. Murphy, R. Hayes, S. Imberti, G. G. Warr and R. Atkin, Phys. Chem. Chem. Phys., 2014, 16, 13182-13190.

35 D. V. Wagle, C. A. Deakyne and G. A. Baker, J. Phys. Chem. B, 2016, 120, 6739-6746.

36 J. Padró, L. Saiz and E. Guàrdia, J. Mol. Struct., 1997, 416, 243-248.

37 (a) J. J. Towey, A. K. Soper and L. Dougan, J. Phys. Chem. B, 2012, 116, 13898-13904; (b) J. J. Towey, A. K. Soper and L. Dougan, Faraday Disc., 2013, 167, 159. 

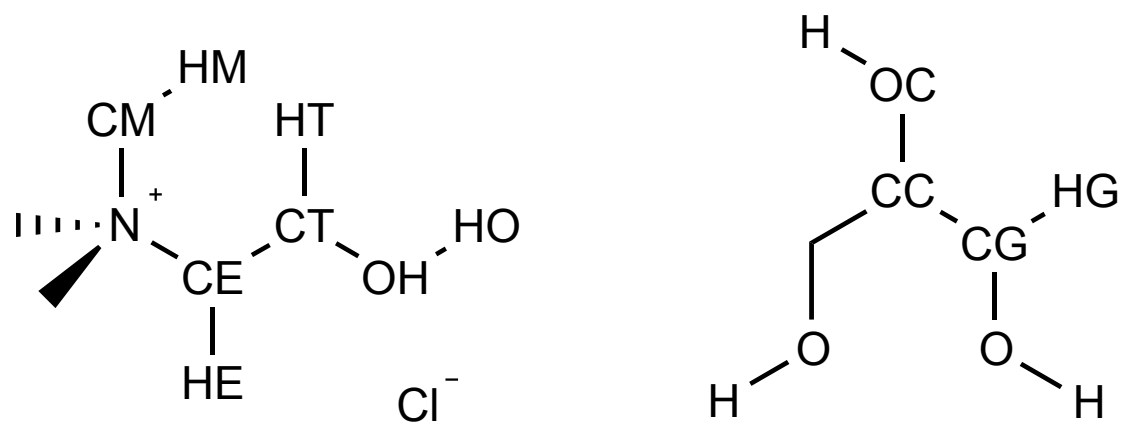

Fig. 1 Atom types assigned to the choline chloride and glycerol components used in the EPSR simulation of the neutron scattering data. 

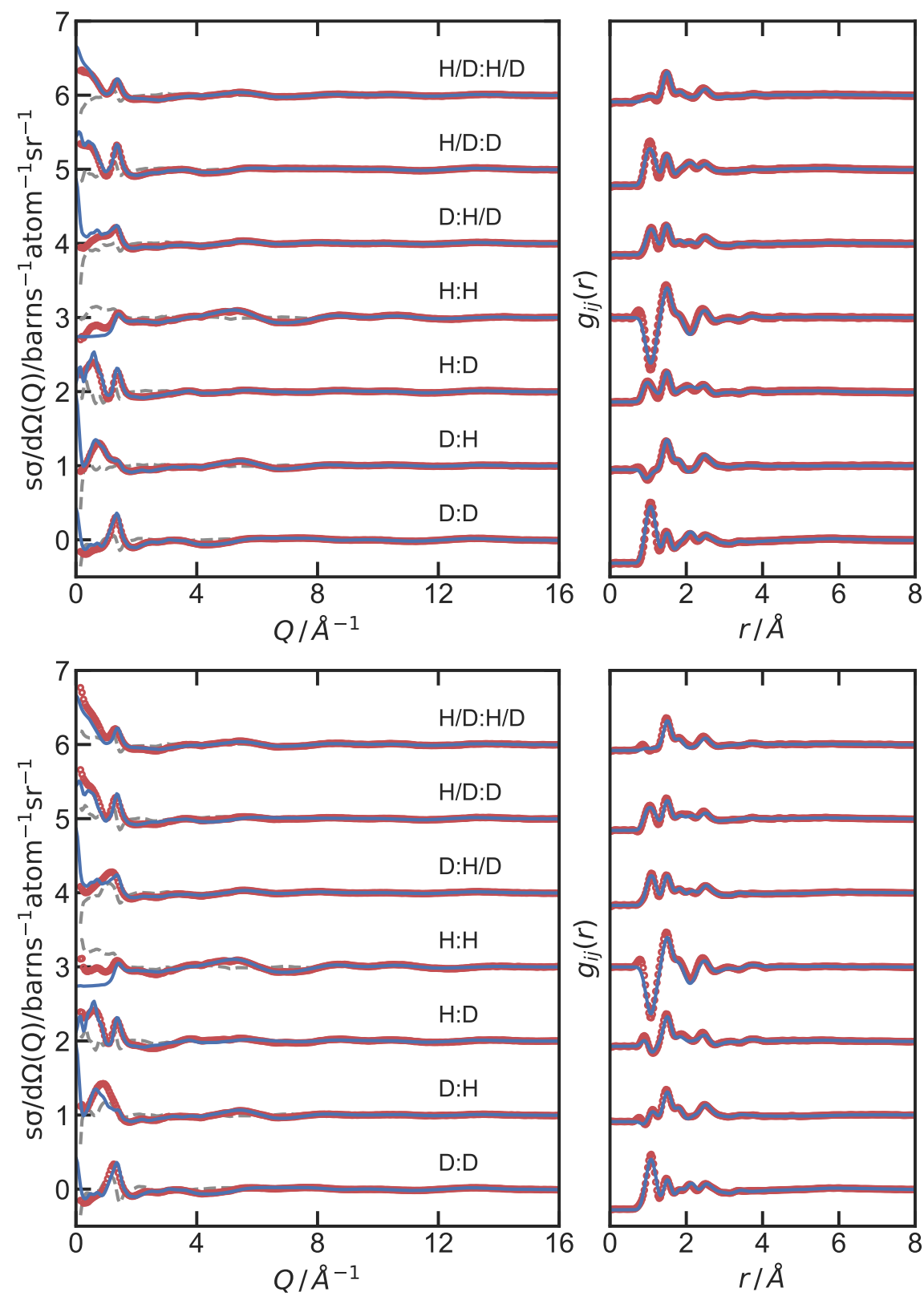

Fig. 2 Comparison of the structure factors (left) and transformations to real space (right) for the experimental (symbols) and EPSR modeled (solid) data for the isotopically $\mathrm{ChCl}$ :Gly $\left(\chi_{\mathrm{ChCl}}=0.33\right)$ (top) and ChCl:Gly $\left(\chi_{\mathrm{ChCl}}=0.50\right)$ (bottom) liquids. Residual differences between the experimental and simulated data are shown by the dashed lines. The curves have been shifted for clarity and are labelled with the isotopic composition of the ChCl:Gly components. 

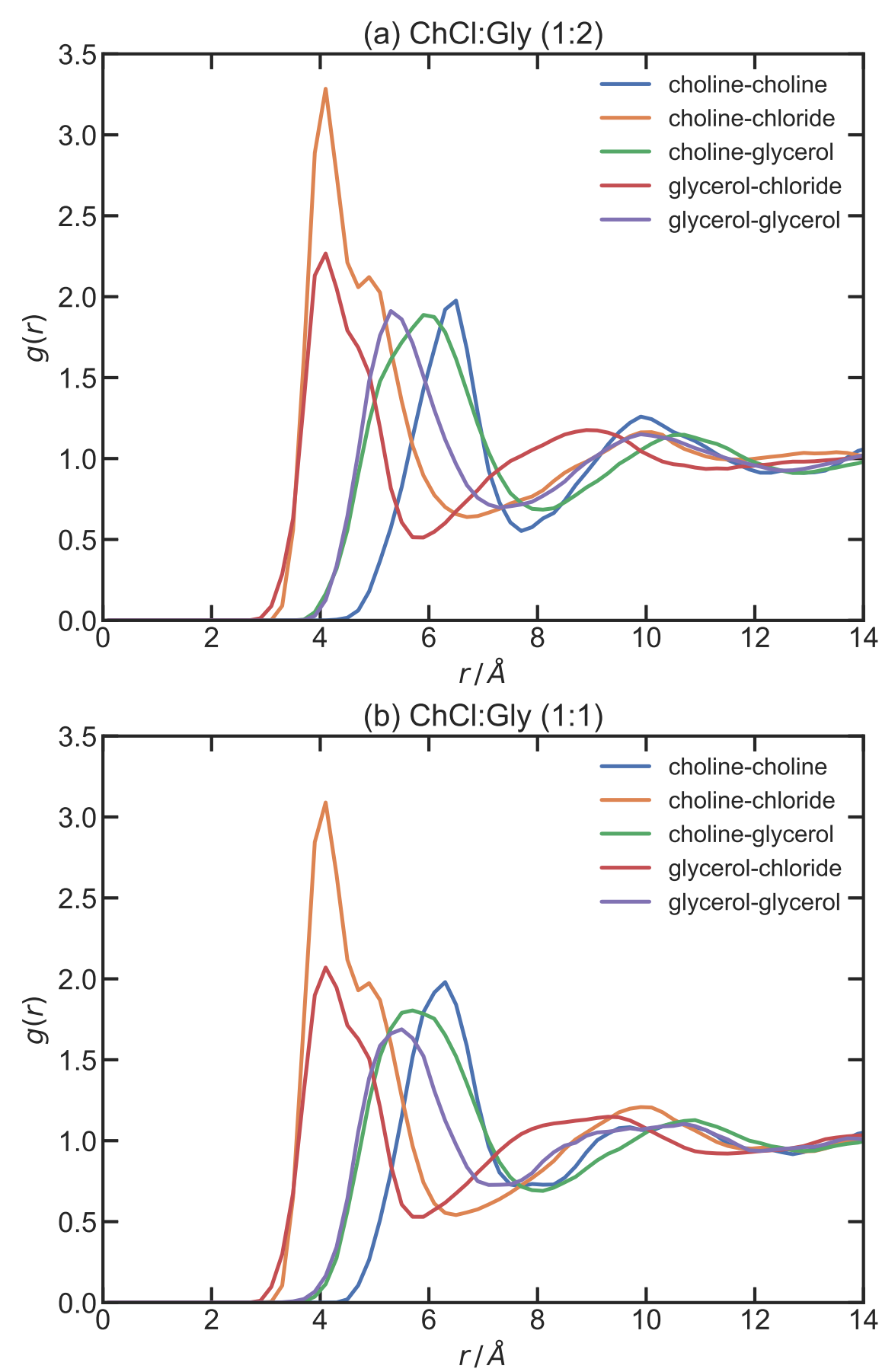

Fig. 3 Centre of mass RDFs for ChCl:Gly $\left(\chi_{\mathrm{ChCl}}=0.33\right)$, top, and ChCl:Gly $\left(\chi_{\mathrm{ChCl}}=0.50\right)$, bottom. 

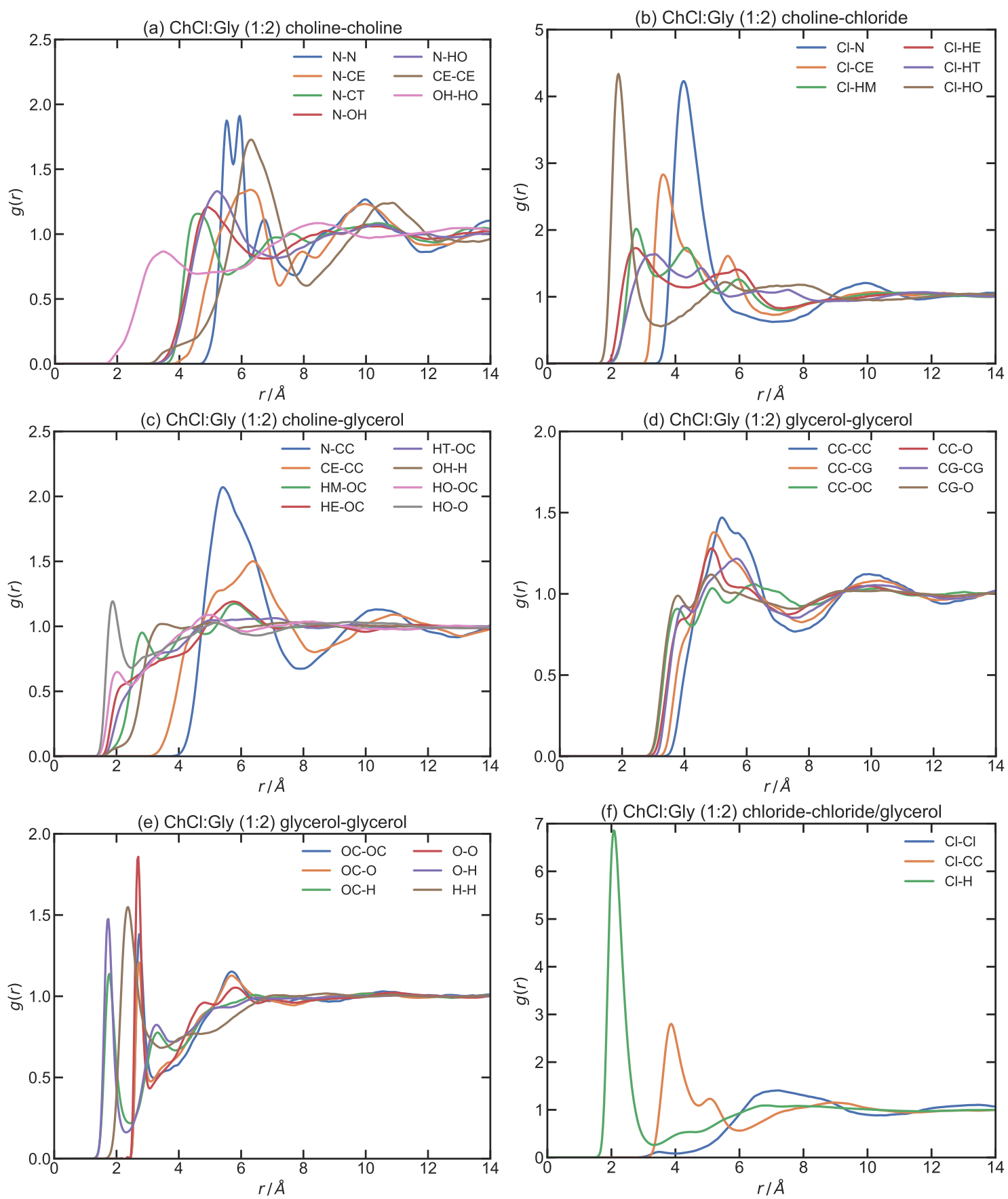

Fig. 4 Atom-centred pRDFs for ChCl:Gly $\left(\chi_{\mathrm{ChCl}}=0.33\right)$. correponding data for ChCl:Gly $\left(\chi_{\mathrm{ChCl}}=0.50\right)$ can be found in Fig. S2 in the ESI. $\dagger$ 

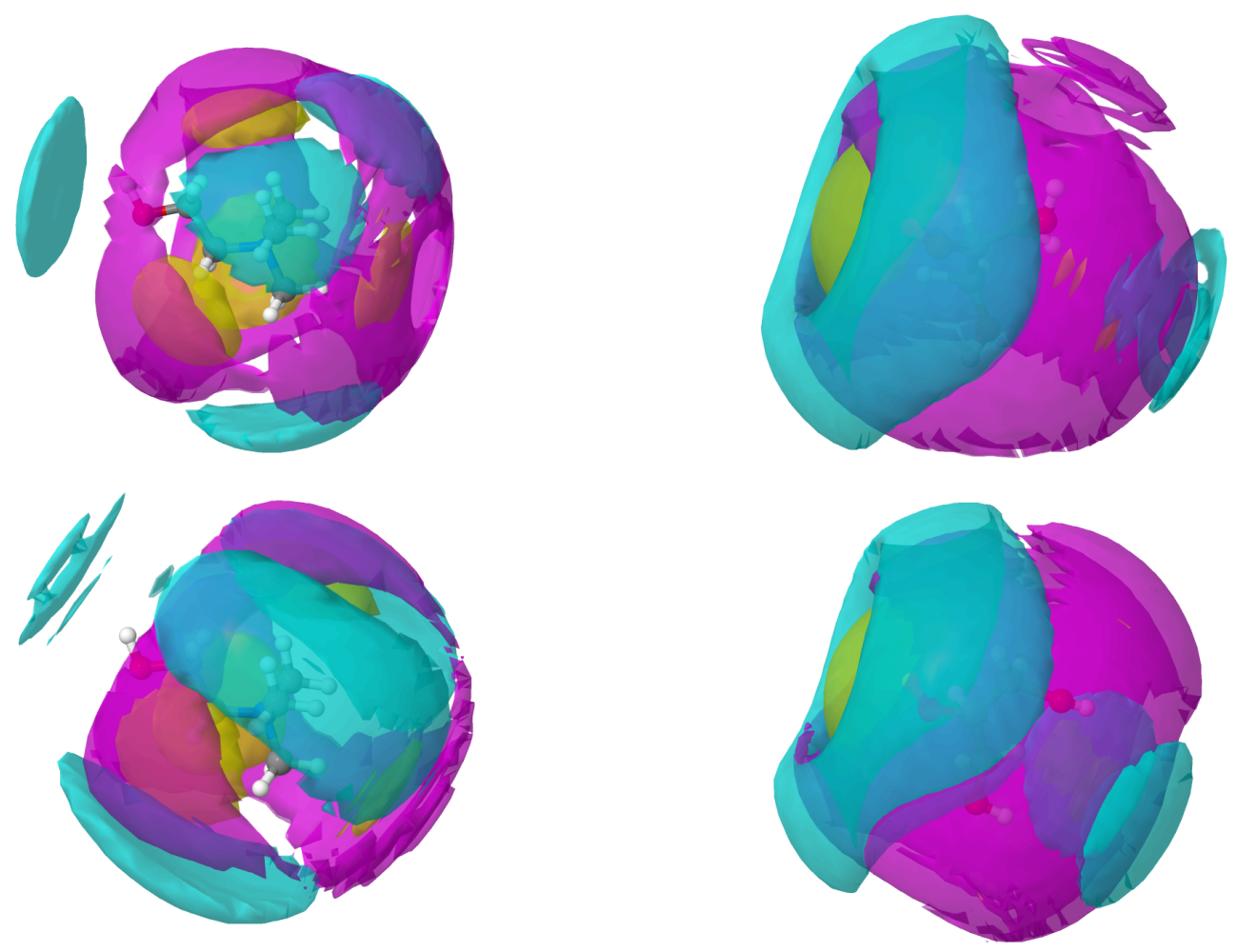

Fig. 5 Centre of mass RDFs for ChCl:Gly $\left(\chi_{\mathrm{ChCl}}=0.33\right)$, top, and ChCl:Gly $\left(\chi_{\mathrm{ChCl}}=0.50\right)$, bottom. Left is around a central choline, right is around central glycerol. Choline (cyan), chloride (yellow), and glycerol (purple). 

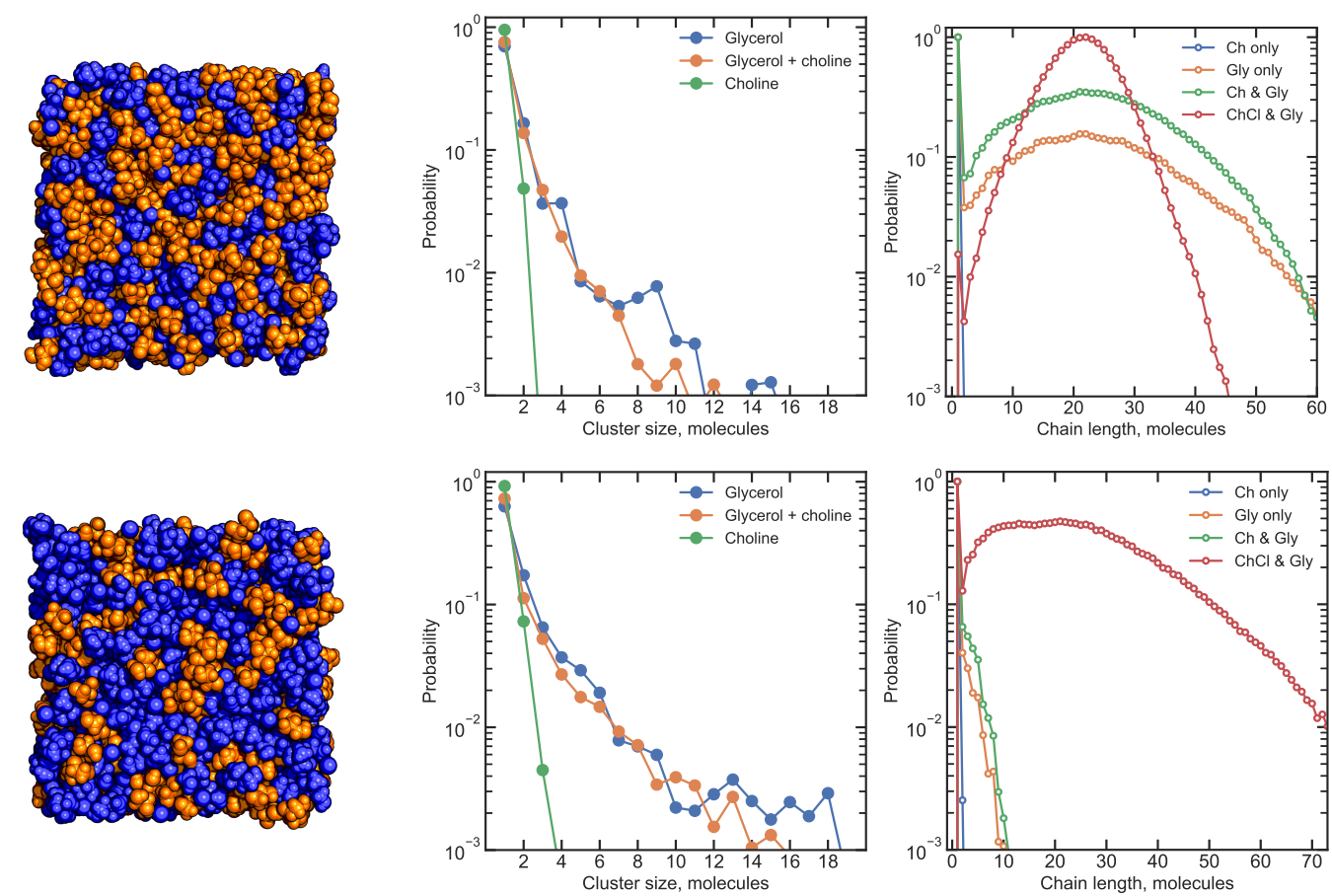

Fig. 6 Snapshots and hydrogen bonding analysis of $\mathrm{ChCl}: \mathrm{Gly}\left(\chi_{\mathrm{ChCl}}=0.33\right.$, top $)$ and ChCl:Gly $\left(\chi_{\mathrm{ChCl}}=\right.$ 0.50 , bottom). Choline chloride highlighted in blue and glycerol in orange. Corresponding cluster distributions showing the strongly interconnected networks of glycerol and chloride anions at both compositions (centre) and hydrogen bonded chain length distributions (right). 


\begin{tabular}{|c|c|c|}
\hline \multirow[b]{2}{*}{$\mathrm{RDF}$} & \multicolumn{2}{|c|}{ Peak Position $(\AA)$} \\
\hline & $\chi_{\mathrm{ChCl}}=0.33$ & $\chi_{\mathrm{ChCl}}=0.50$ \\
\hline choline-choline & 6.5 & 6.3 \\
\hline choline- $\mathrm{Cl}^{-}$ & 4.1 & 4.1 \\
\hline choline-glycerol & 5.9 & 5.7 \\
\hline glycerol-Cl- & 4.1 & 4.1 \\
\hline glycerol-glycerol & 5.3 & 5.5 \\
\hline
\end{tabular}

Table 1 Position of the first peak in the COM radial distribution functions for $\mathrm{ChCl}$ :Gly $\left(\chi_{\mathrm{ChCl}}=0.33\right.$ and $0.50)$ 
Table 2 Coordination numbers calculated for the principle partial RDFs shown in Figure 4 for $\mathrm{ChCl:Gly}$ $\left(\chi_{\mathrm{ChCl}}=0.33\right)$ and ChCl:Gly $\left(\chi_{\mathrm{ChCl}}=0.50\right)$ DES. Mean coordination numbers $N_{\text {coord }}$ were determined to the first minima $\left(r_{\min }\right)$ after the primary correlation peak $\left(r_{\max }\right)$ in the pRDF.

\begin{tabular}{|c|c|c|c|c|}
\hline \multirow[t]{2}{*}{$\mathrm{pRDF}$} & \multicolumn{2}{|c|}{ ChCl:Gly $\left(\chi_{\mathrm{ChCl}}=0.33\right)$} & \multicolumn{2}{|c|}{ ChCl:Gly $\left(\chi_{\mathrm{ChCl}}=0.50\right)$} \\
\hline & $r_{\max }\left(r_{\min }\right) / \AA$ & $N_{\text {coord }}$ & $r_{\max }\left(r_{\min }\right) / \AA$ & $N_{\text {coord }}$ \\
\hline \multicolumn{5}{|c|}{ Choline-Choline } \\
\hline $\mathrm{N}-\mathrm{N}$ & $5.5(6.4)$ & $2.5 \pm 0.9$ & $5.7(6.4)$ & $3.5 \pm 1.1$ \\
\hline $\mathrm{CE}-\mathrm{CE}$ & $6.4(8.1)$ & $4.8 \pm 1.4$ & $6.3(8.1)$ & $6.9 \pm 1.7$ \\
\hline $\mathrm{CE}-\mathrm{N}$ & $6.2(7.2)$ & $3.5 \pm 1.1$ & $6.1(7.2)$ & $4.9 \pm 1.3$ \\
\hline $\mathrm{N}-\mathrm{CT}$ & $4.6(5.6)$ & $1.9 \pm 0.9$ & $4.7(5.6)$ & $2.4 \pm 1.0$ \\
\hline $\mathrm{N}-\mathrm{OH}$ & $4.9(6.8)$ & $3.0 \pm 1.3$ & $4.9(6.8)$ & $4.2 \pm 1.5$ \\
\hline $\mathrm{N}-\mathrm{HO}$ & $5.2(7.2)$ & $3.6 \pm 1.5$ & $5.1(7.2)$ & $5.1 \pm 1.6$ \\
\hline $\mathrm{OH}-\mathrm{HO}$ & $3.5(4.5)$ & $1.5 \pm 0.6$ & $3.4(4.5)$ & $1.7 \pm 0.8$ \\
\hline \multicolumn{5}{|c|}{ Choline-Chloride } \\
\hline $\mathrm{N}-\mathrm{Cl}$ & $4.3(6.5)$ & $3.1 \pm 1.1$ & $4.2(6.5)$ & $4.1 \pm 1.0$ \\
\hline $\mathrm{CE}-\mathrm{Cl}$ & $3.6(5.2)$ & $1.6 \pm 0.9$ & $3.7(5.2)$ & $2.2 \pm 0.8$ \\
\hline Cl-HM & $2.8(3.4)$ & $3.2 \pm 1.7$ & $2.9(3.4)$ & $4.2 \pm 2.0$ \\
\hline $\mathrm{Cl}-\mathrm{HE}$ & $2.8(4.2)$ & $1.5 \pm 1.3$ & $2.7(4.2)$ & $2.0 \pm 1.4$ \\
\hline Cl-HT & $3.3(4.3)$ & $1.6 \pm 1.4$ & $3.2(4.3)$ & $2.2 \pm 1.6$ \\
\hline $\mathrm{Cl}-\mathrm{HO}$ & $2.2(3.5)$ & $0.4 \pm 0.6$ & $2.2(3.5)$ & $0.7 \pm 0.8$ \\
\hline \multicolumn{5}{|c|}{ Choline-Glycerol } \\
\hline $\mathrm{N}-\mathrm{CC}$ & $5.4(7.8)$ & $8.4 \pm 1.6$ & $5.4(7.8)$ & $5.9 \pm 1.8$ \\
\hline CE-CC & $6.4(8.3)$ & $10 \pm 1.8$ & $6.5(8.3)$ & $6.9 \pm 1.9$ \\
\hline $\mathrm{HM}-\mathrm{O}$ & $2.9(3.4)$ & $0.5 \pm 0.6$ & $2.9(3.4)$ & $0.4 \pm 0.6$ \\
\hline $\mathrm{HE}-\mathrm{O}$ & $3.4(4.2)$ & $1.5 \pm 1.0$ & $3.5(4.2)$ & $1.0 \pm 0.9$ \\
\hline HT-O & $3.6(4.1)$ & $1.6 \pm 1.0$ & $3.5(4.1)$ & $1.1 \pm 1.0$ \\
\hline $\mathrm{OH}-\mathrm{H}$ & $3.4(4.3)$ & $3.1 \pm 1.4$ & $3.5(4.3)$ & $2.1 \pm 1.4$ \\
\hline $\mathrm{HO}-\mathrm{O}$ & $1.9(2.5)$ & $0.4 \pm 0.5$ & $1.9(2.5)$ & $0.2 \pm 0.4$ \\
\hline \multicolumn{5}{|c|}{ Glycerol-Chloride } \\
\hline $\mathrm{Cl}-\mathrm{CC}$ & $3.9(4.7)$ & $2.0 \pm 1.0$ & $3.9(4.7)$ & $1.3 \pm 1.0$ \\
\hline $\mathrm{Cl}-\mathrm{H}$ & $2.1(3.4)$ & $3.2 \pm 1.4$ & $2.1(3.4)$ & $2.1 \pm 1.3$ \\
\hline \multicolumn{5}{|c|}{ Glycerol-Glycerol } \\
\hline CC-CC & $5.2(7.50)$ & $7.5 \pm 1.7$ & $5.0(7.50)$ & $4.9 \pm 1.5$ \\
\hline CC-CG & $4.9(7.50)$ & $15 \pm 3.0$ & $4.95(7.50)$ & $11.5 \pm 3.1$ \\
\hline $\mathrm{CC}-\mathrm{OC}$ & $3.8(4.30)$ & $1.6 \pm 0.7$ & $3.7(4.30)$ & $1.3 \pm 0.5$ \\
\hline $\mathrm{CC}-\mathrm{OC}$ & $4.9(5.40)$ & $2.9 \pm 1.2$ & $4.9(5.40)$ & $2.4 \pm 1.0$ \\
\hline $\mathrm{CC}-\mathrm{O}$ & $4.9(7.20)$ & $13.3 \pm 2.6$ & $4.9(7.20)$ & $7.7 \pm 2.2$ \\
\hline CG-CG & $5.7(7.40)$ & $14.4 \pm 2.9$ & $5.5(7.40)$ & $11.5 \pm 3.0$ \\
\hline CG-O & $4.8(7.30)$ & $13.8 \pm 2.7$ & $4.8(7.30)$ & $10.7 \pm 2.7$ \\
\hline $\mathrm{OC}-\mathrm{OC}$ & $2.7(3.20)$ & $1.2 \pm 0.4$ & $2.7(3.20)$ & $1.1 \pm 0.3$ \\
\hline $\mathrm{OC}-\mathrm{O}$ & $2.7(3.10)$ & $1.1 \pm 0.9$ & $2.7(3.10)$ & $0.9 \pm 0.8$ \\
\hline $\mathrm{OC}-\mathrm{H}$ & $1.8(2.40)$ & $1.3 \pm 0.5$ & $1.8(2.40)$ & $1.2 \pm 0.4$ \\
\hline $\mathrm{O}-\mathrm{O}$ & $2.7(3.05)$ & $1.5 \pm 0.6$ & $2.7(3.05)$ & $1.3 \pm 0.6$ \\
\hline $\mathrm{O}-\mathrm{H}$ & $1.7(2.30)$ & $1.3 \pm 0.5$ & $1.8(2.30)$ & $1.2 \pm 0.4$ \\
\hline $\mathrm{H}-\mathrm{H}$ & $2.4(3.40)$ & $2.9 \pm 1.2$ & $2.4(3.40)$ & $2.4 \pm 1.0$ \\
\hline \multicolumn{5}{|c|}{ Chloride-Chloride } \\
\hline $\mathrm{Cl}-\mathrm{Cl}$ & $7.1(10.3)$ & $10.1 \pm 2.5$ & $7.0(10.3)$ & $13.4 \pm 2.1$ \\
\hline
\end{tabular}


Table 3 Coordination numbers calculated to $r_{\min }$ at $2.5 \AA$ to encompass all hydrogen bond associations within the first correlation shell for ChCl:Gly $\chi_{\mathrm{ChCl}}=0.33$ and 0.50 .

\begin{tabular}{lcc}
\hline H-Bond & $N_{\text {coord }}\left(\chi_{\text {ChCl }}=0.33\right)$ & $N_{\text {coord }}\left(\chi_{\text {ChCl }}=0.50\right)$ \\
\hline Cl-H & $2.44 \pm 1.20$ & $1.62 \pm 1.11$ \\
Cl-HO & $0.24 \pm 0.47$ & $0.39 \pm 0.61$ \\
OC-H & $1.38 \pm 0.54$ & $1.23 \pm 0.46$ \\
OC-HO & $0.05 \pm 0.22$ & $0.08 \pm 0.26$ \\
O-H & $1.37 \pm 0.53$ & $1.24 \pm 0.45$ \\
O-HO & $0.09 \pm 0.29$ & $0.12 \pm 0.34$ \\
OH-H & $0.06 \pm 0.24$ & $0.03 \pm 0.17$ \\
OH-HO & $1.01 \pm 0.11$ & $1.02 \pm 0.15$ \\
\hline
\end{tabular}

